\title{
RBM38 is negatively regulated by miR-320b and enhances Adriamycin resistance in breast cancer cells
}

\author{
JING KE, KAN NI, HUIMIN XUE and JIA LI \\ Department of General Surgery, Affiliated Hospital of Nantong University, Nantong, Jiangsu 226021, P.R. China
}

Received January 7, 2021; Accepted September 22, 2021

DOI: $10.3892 / 01.2021 .13145$

\begin{abstract}
Breast cancer (BC) is a common type of malignant tumor that is frequently accompanied by drug resistance, which is a significant challenge in the treatment of BC. Adriamycin (ADM) is a commonly used drug for the treatment of BC. The aim of the present study was to demonstrate the association between RNA binding motif protein 38 (RBM38) and ADM resistance in $\mathrm{BC}$. The results revealed that the expression levels of RBM38 were significantly upregulated in ADM-resistant BC tissues and the ADM-resistant cell line, MCF-7/A, as demonstrated using reverse transcription-quantitative PCR and western blotting. In addition, the results of the MTT assay revealed that the overexpression of RBM38 enhanced the resistance of MCF-7/A cells to ADM, promoted invasiveness, as determined using a Transwell assay, inhibited the apoptosis of resistant cells, as determined using flow cytometry, and accelerated cell cycle progression from the $G_{0}$ to the $S$ phase. The results of the dual luciferase reporter assay demonstrated the binding relationship between microRNA (miR)-320b and RBM38, and the expression levels of miR-320b were significantly downregulated in ADM-resistant BC tissues and MCF-7/A cells. Overexpression of miR-320b reversed ADM resistance, suppressed invasiveness, promoted apoptosis and arrested MCF-7/A cells in the $\mathrm{G}_{0}$ phase. In addition, RBM38 was discovered to be negatively regulated by $\mathrm{miR}-320 \mathrm{~b}$, which was able to restore the sensitivity of BC cells to ADM by downregulating RBM38. Further exploration of the underlying regulatory mechanism revealed that the miR-320b/RBM38 signaling axis mediated the development of $\mathrm{ADM}$ resistance in $\mathrm{BC}$ by altering the expression of cell cycle-, drug resistance- and PI3K/AKT signaling pathway-related proteins. In conclusion, the results of the present study suggested that RBM38 may be negatively regulated by miR-320b, which accelerates drug resistance in $\mathrm{BC}$.
\end{abstract}

Correspondence to: Dr Jia Li, Department of General Surgery, Affiliated Hospital of Nantong University, 20 Xisi Road, Nantong, Jiangsu 226021, P.R. China

E-mail: ljseu1@163.com

Key words: microRNA-320b, RNA binding motif protein 38, breast cancer, Adriamycin resistance

\section{Introduction}

Breast cancer (BC) is the most common type of malignant tumor (1); two million new BC cases were diagnosed in 2018 (23\% of all cancers), and the disease ranks second in mortality rate overall worldwide (10.9\% of all cancers) (2). The majority of patients initially respond well to treatment; however, BC cells gradually develop resistance to conventional radiotherapy and chemotherapy, which can result in treatment failure (3). Drug resistance during BC treatment was found to be regulated by several different mechanisms, including somatic mutations, epigenetic modifications and aberrant changes in signaling pathways, as well as influences from tumor microenvironment-induced modifications to drug transport systems (4-6).

MicroRNAs (miRNAs/miRs) are a type of non-coding endogenous RNA of 20-25 nucleotides in length, that bind to the 3'-untranslated region of target mRNAs to induce degradation or translational inhibition, thereby negatively regulating gene expression (7-9). Previous studies have reported that miRNAs play an important role in reversing tumor drug resistance (10). In fact, evidence has suggested that the abnormal expression of miRNAs, including miRNA-449, miR-140 and miR-200a, promotes drug resistance in $\mathrm{BC}$ (11-13). Furthermore, the abnormal expression of multiple miRNAs in $\mathrm{BC}$ was found to be pathologically associated with radiotherapy and multidrug resistance, including resistance to chemotherapy, endocrine therapy and targeted therapy $(14,15)$. Among the different miRNAs identified to date, miR-320b was discovered to be involved in the development of colorectal cancer, nasopharyngeal carcinoma and osteosarcoma by regulating several processes, such as tumor cell proliferation, metastasis and invasion, via targeting various signaling pathways (16-18). Therefore, further investigations into the specific roles of miRNAs in the development of drug resistance in $\mathrm{BC}$ are likely to be of great clinical significance.

RNA binding proteins (RBPs) have a high affinity towards miRNAs, and are involved in RNA splicing, polyadenylation, sequence editing, RNA transport, maintenance of RNA stability and degradation, intracellular localization and translation regulation (19). RNA binding motif protein 38 (RBM38) is located at chromosome 20q13 and belongs to the RNA recognition motif RBP family (20). Previous studies have reported that RBM38 suppresses cellular migration and invasiveness in $\mathrm{BC}$ by directly binding to estrogen receptor- $\alpha$ transcripts or 
the tumor suppressor mutant, p53 (21,22). Adriamycin (ADM) is the current drug used for combination adjuvant $\mathrm{BC}$ treatment (23). However, ADM resistance frequently occurs following BC treatment (24). Although studies have demonstrated that RBM38 is closely associated with the inhibition of BC tumorigenesis $(21,25)$, the present study aimed to further determine whether RBM38 facilitated ADM resistance in BC. By utilizing PCR, western blotting, Transwell assays and flow cytometry, regulation of the miR-320b/RBM38 signaling axis in drug-resistant $\mathrm{BC}$ was further investigated.

\section{Materials and methods}

Patient studies. A total of 5 ADM-sensitive and 5 ADM-resistant BC samples were obtained from patients with BC (age range, 33-55 years), cryopreserved in liquid nitrogen and then stored at $-80^{\circ} \mathrm{C}$. These patients only treated with ADM or ADM combined therapy and underwent surgery at the Affiliated Hospital of Nantong University (Nantong, China) between January 2017 and December 2018 were included in this study. The experimental protocol was approved by the ethics committee of The Affiliated Hospital of Nantong University (approval no. 2019032174; Nantong, China), and was performed in accordance with the principles of the 1964 Declaration of Helsinki. All patients provided written informed consent prior to the commencement of the study.

Cell lines and culture. The human ADM-sensitive BC cell line, MCF-7/S, and human ADM-resistant BC cell line, MCF-7/A, were both purchased from the American Type Culture Collection. The cells were cultured in DMEM supplemented with 10\% FBS and $100 \mathrm{U} / \mathrm{ml}$ penicillin (all Gibco; Thermo Fisher Scientific, Inc.), and maintained at $37^{\circ} \mathrm{C}$ with $5 \% \mathrm{CO}_{2}$.

Reverse transcription-quantitative (RT-q) PCR. For RT-qPCR analysis, MCF-7/S and MCF-7/A cells were harvested in the logarithmic growth phase, and the clinical BC samples were ground using liquid nitrogen. Total RNA was extracted from the cells and tissue samples using TRIzol ${ }^{\circledR}$ reagent (Invitrogen; Thermo Fisher Scientific, Inc.) for $5 \mathrm{~min}$ at $25^{\circ} \mathrm{C}$. Then, $200 \mu \mathrm{l}$ chloroform was added to the solution for an additional $15 \mathrm{~min}$ at $25^{\circ} \mathrm{C}$. The mixture was centrifuged at $12,000 \times$ g at $4{ }^{\circ} \mathrm{C}$ for $15 \mathrm{~min}$ to obtain the RNA sediment, and $0.5 \mathrm{ml}$ isopropyl alcohol was then added. The RNA extract was dried and stored at $-80^{\circ} \mathrm{C}$ until required.

Total RNA was reverse transcribed into cDNA using the PrimeScript RT Reagent kit (Takara Biotechnology Co., Ltd.) according to the manufacturer's protocol. qPCR analysis of RBM38 and miR-320b expression was subsequently performed using a SYBR Prime Script RT-PCR kit (Takara Biotechnology Co., Ltd.), according to the manufacturer's instructions. The following thermocycling conditions were used for amplification: $94^{\circ} \mathrm{C}$ for $10 \mathrm{~min}$, followed by 40 cycles of $94^{\circ} \mathrm{C}$ for $30 \mathrm{sec}$, $55-58^{\circ} \mathrm{C}$ for $30 \mathrm{sec}$, and $72^{\circ} \mathrm{C}$ for $45 \mathrm{sec}$, and a final cycle at $72^{\circ} \mathrm{C}$ for $10 \mathrm{~min}$. Relative expression levels of RBM38 and miR-320b were calculated using the $2^{-\Delta \Delta \mathrm{Cq}}$ method (26), and RBM38 expression was normalized to that of $\beta$-actin expression, while miR-320b was normalized to U6 expression. The primers used were: RBM38 forward 5'-TGAACTTTGACGGGAGGAGC-3' and reverse, 5'-TGATGGGGTTCGGGTCTTTG-3'; $\beta$-actin forward, 5'-CTTCGCGGGCGACGAT-3' and reverse, 5'-ACA TAGGAATCCTTCTGACCCA-3'; miR-320b forward, 5'-GAT GCTGAAAAGCTGGGTTG-3' and reverse, 5'-TATGGTTGTT CTGCTCTCTGTCTC-3'; U6 forward, 5'-CTCGCTTCGGCA GCACA-3' and reverse, 5'-AACGCTTCACGAATTTGCGT-3'.

Transfection. Small interfering RNA (siRNA/si) targeting RBM38 (siR-RBM38, $20 \mathrm{nM}$ ), siR-negative control (NC, $20 \mathrm{nM}$ ), pcDNA3.1-RBM38 overexpression vector $(4 \mu \mathrm{g} / \mathrm{ml})$, pcDNA3.1 empty vector (acting as the overexpression $\mathrm{NC}, 4 \mu \mathrm{g} / \mathrm{ml}$ ), miR-320b inhibitor (50 nM), inhibitor NC (50 nM), miR-320b mimics $(50 \mathrm{nM})$ and mimics $\mathrm{NC}(50 \mathrm{nM})$ were purchased from Shanghai GenePharma Co., Ltd. The constructs were transfected into MCF-7/A cells using Lipofectamine ${ }^{\circledR} 2000$ (Invitrogen; Thermo Fisher Scientific, Inc.) at $37^{\circ} \mathrm{C}$ for $48 \mathrm{~h}$ according to the manufacturer's protocol. The sequences used were: siR-NC, forward, 5'-UUCUCCGAACGUGUCACGUTT-3' and reverse, 5'-ACGUGACACGUUCGGAGAATT-3'; siR-RBM38, forward, 5'-CCAGACGGGCUUUGCCAUUTT-3' and reverse, 5'-AAUGGCAAAGCCCGUCUGGTT-3'; miR-320b inhibitor, 5'-UUGCCCUCUCAACCCAGCUUUU-3'; inhibitor NC, 5'-CAGUACUUUUGUGUAGUACAA-3'; miR-320b mimics, forward, 5'-AAAAGCUGGGUUGAGAGGGCAA-3' and reverse, 5'-GCCCUCUCAACCCAGCUUUUUU-3'; and mimics NC, forward, 5'-UUCUCCGAACGUGUCACGUTT-3' and reverse, 5'-ACGUGACACGUUCGGAGAATT-3'. The following studies were conducted $48 \mathrm{~h}$ after transfection.

MTT assay. Briefly, 5x10³ MCF-7/A cells/well were seeded into 96-well plates and incubated with $100 \mu \mathrm{l} \mathrm{DMEM}$ at $37^{\circ} \mathrm{C}$ $\left(5 \% \mathrm{CO}_{2}\right)$. After a $24-\mathrm{h}$ incubation period, the cells were treated with increasing concentrations of $\operatorname{ADM}(1,2.5,5$, $10,20,40,80,160$ and $320 \mu \mathrm{M})$ in DMEM containing $10 \%$ FBS for $48 \mathrm{~h}$ at $37^{\circ} \mathrm{C}$. Subsequently, $20 \mu \mathrm{l}$ MTT reagent was added per well, and the cells cultured for a further $4 \mathrm{~h}$ at $37^{\circ} \mathrm{C}$. Following incubation, $150 \mu \mathrm{l}$ DMSO was added to each well to dissolve the purple formazan crystals, and the absorbance was measured within $10 \mathrm{~min}$ at a wavelength of $570 \mathrm{~nm}$ (OD570) using a microplate reader.

Transwell assay. The invasive ability of MCF-7/A cells was analyzed using a Transwell assay. Briefly, $200 \mu \mathrm{l}$ cell suspension (1x $10^{5}$ cells/well) was plated into the Matrigel-precoated upper chamber (cat. no. 356234; BD Biosciences) of a 24-well Transwell plate (Corning, Inc.; pore size, $8-\mu \mathrm{m}$ ). The upper chamber was filled with $50 \mu \mathrm{l}$ serum-free DMEM medium supplemented with 10 g/l BSA (Thermo Fisher Scientific, Inc.), while the lower chamber was filled with DMEM containing 10\% FBS. Following a $72 \mathrm{~h}$-incubation period at $37^{\circ} \mathrm{C}$, the invasive cells were fixed with $4 \%$ phosphate-buffered neutral formalin at room temperature for $20 \mathrm{~min}$ and then washed with PBS for three times, then stained by crystal violet for $5 \mathrm{~min}$ at room temperature. Invasive cells were visualized in five randomly selected fields of view using an inverted light microscope (Olympus Corporation).

Western blotting. Total protein was extracted from MCF-7/A cells using RIPA lysis buffer (Beyotime Institute of Biotechnology) supplemented with $1 \%$ PMSF. Total protein was quantified using a BCA protein assay kit, $50 \mu \mathrm{g}$ protein was resolved by 5 or $10 \%$ SDS-PAGE, and then transferred to PVDF membranes 


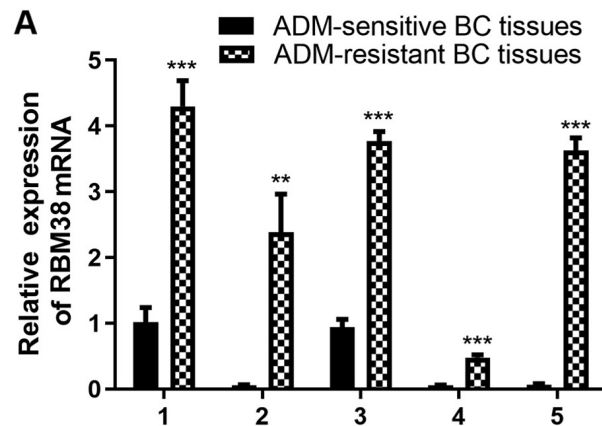

B

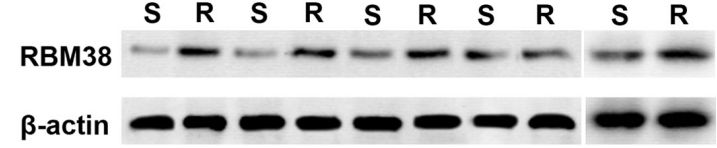

C

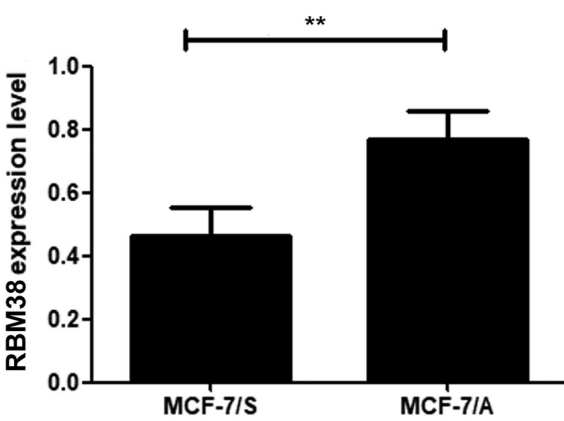

D

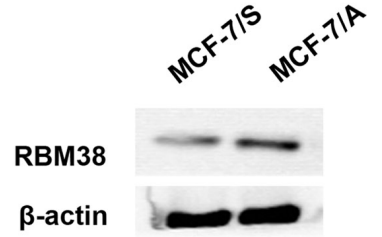

Figure 1. Expression levels of RBM38 in BC tissues and cells. (A) RBM38 expression was upregulated in ADM-resistant compared with ADM-sensitive BC tissues. (B) RBM38 expression was upregulated in MCF-7/A cells compared with MCF-7/S cells. (C) mRNA and (D) protein expression levels of RBM38 in MCF-7/S and MCF-7/A cells. ${ }^{* *} \mathrm{P}<0.01$ and ${ }^{* * *} \mathrm{P}<0.001$. RBM38, RNA binding motif protein 38; BC, breast cancer; ADM, Adriamycin; S, ADM-sensitive cells; A, ADM-resistant cells.

(EMD Millipore). The membranes were blocked with 5\% non-fat milk in $0.1 \%$ Tris-buffered saline-Tween (TBST) at room temperature for $2 \mathrm{~h}$, and then incubated with primary antibodies (all from Abcam) against RBM38 (cat. no. ab200403), phosphorylated (p)-PI3K (cat. no. ab182651), PI3K (cat. no. ab32089), p-AKT (cat. no. ab38449), AKT (cat. no. ab8805), Bax (cat. no. ab32503), Bcl-2 (cat. no. ab32124), breast cancer resistance protein (BCRP; cat. no. ab207732), multiple drug resistant protein 1 (MDR1; cat. no. ab170904) and $\beta$-actin (cat. no. ab8226) diluted at $1: 1,000$ at $4^{\circ} \mathrm{C}$ overnight with gentle rocking. $\beta$-actin served as the internal loading control. After washing with TBST, the membranes were incubated with the appropriate horseradish peroxidase-conjugated secondary antibodies (SA00001-1 or SA00001-2; ProteinTech Group, Inc.) diluted at 1:2,000 for $2 \mathrm{~h}$ at $37^{\circ} \mathrm{C}$. After extensive washing with TBST, the proteins were visualized using an ECL detection kit in accordance with the manufacturer's recommendations (EMD Millipore). The integrated density of the bands was quantified using Image Lab software version 6.1 (Bio-Rad Laboratories, Inc.).

Flow cytometric analysis of apoptosis and the cell cycle. Cell cycle distribution and apoptosis levels were analyzed via flow cytometry after transfection. Both the Annexin V-FITC Apoptosis Detection and Cell Cycle Detection kits were purchased from Nanjing KeyGen Biotech Co., Ltd., and used according to the manufacturers' protocols. The staining buffer contained RNase and the cells were permeabilized for cell cycle assay. The apoptosis ratio was calculated as the percentage of early plus late apoptotic cells.

Dual luciferase reporter assay. The binding microRNAs of RBM38 were predicted by miRanda algorithm (http://www. microrna.org/microrna/home.do) and the interaction was demon- strated by dual luciferase reporter assay. The wild-type (WT) or mutated (Mut) RBM38 sequences were inserted into the pGL3 vector (Promega Corporation) to construct luciferase reporter plasmids, which were subsequently co-transfected with a miR-320b mimics or mimic NC into cells using Lipofectamine $^{\circledR} 2000$ (Invitrogen; Thermo Fisher Scientific, Inc.), according to the manufacturer's protocol. Following $24 \mathrm{~h}$ of incubation, the relative Firefly luciferase activity was determined using a Dual Luciferase Reporter assay system (Promega Corporation), and normalized to that of Renilla luciferase.

Statistical analysis. Statistical analysis was performed using SPSS 13.0 (SPSS, Inc.) or GraphPad Prism 7.0 (GraphPad Software, Inc.) software. Data are presented as the mean \pm SD of triplicate measurements. Two-tailed unpaired Student's t-test was used to determine statistical differences between two groups, while multiple comparisons between groups were performed using one-way ANOVA followed by a Tukey's post hoc test. $\mathrm{P}<0.05$ was considered to indicate a statistically significant difference.

\section{Results}

RBM38 expression levels are upregulated in ADM-resistant BC tissues and cell lines. Although a previous study reported that RBM38 expression levels were upregulated in BC tissues (25), to the best of our knowledge, the present study was the first to identify differences in RBM38 expression between ADM-sensitive and ADM-resistant BC tissues and cells. The expression levels of RBM38 in ADM-resistant BC tissues were first analyzed using RT-qPCR. The results revealed that RBM38 expression was significantly upregulated in ADM-resistant BC tissues compared with that in ADM-sensitive BC tissues (Fig. 1A and B). MCF-7 
cells are a common cell line used to study $\mathrm{BC}$, and numerous studies have used MCF-7/S and MCF-7/A cells to investigate the underlying mechanism of ADM resistance therein (27-29). Therefore, these cell lines were also used in the present study. The differences in proliferation between MCF-7/S and MCF-7/A cells were initially determined. Notably, the proliferative ability of MCF-7/A cells was found to be significantly increased compared with that of MCF-7/S cells (Fig. S1). The expression levels of RBM38 in both MCF-7/S and MCF-7/A cells were also determined. The results demonstrated that RBM38 mRNA and protein expression levels were upregulated in MCF-7/A cells compared with those in MCF-7/S cells (Fig. 1C and D). These results prompted further investigation into the association between RBM38 and ADM resistance in BC.

Overexpression of $R B M 38$ increases the resistance of $M C F-7 / A$ cells to ADM. To further investigate the role that RBM38 plays in ADM-resistant BC, the MCF-7/A cell line was used in subsequent experiments. siR-NC and siR-RBM38, or pcDNA3.1 and pcDNA3.1-RBM38, were separately transfected into MCF-7/A cells for RBM38-knockdown or overexpression experiments, respectively; transfection efficiency was determined using RT-qPCR and western blotting. The results revealed that transfection with siR-RBM38 significantly downregulated the expression levels of RBM38, while transfection with pcDNA3.1-RBM38 upregulated expression levels, compared with the respective controls (Fig. 2A and B). Next, the $\mathrm{IC}_{50}$ values of $\mathrm{ADM}$ across the different groups were determined using an MTT assay. RBM38-knockdown cells exhibited lower $\mathrm{IC}_{50}$ values compared with the corresponding RBM38-overexpressing cells (Fig. 2C), which suggested that RBM38 may affect the sensitivity of BC cells to ADM. A Transwell assay was also used to investigate the effect of RBM38 on the invasiveness of ADM-resistant BC cells. Invasion ability was significantly decreased in siR- RBM38 group compared with siR-NC group, while the invasive ability was markedly increased in the pcDNA3.1-RBM38 group compared with the pcDNA3.1 group (Fig. 2D), which suggested that RBM38 may decrease ADM resistance in BC cells by increasing their invasive capacity.

Furthermore, the effects of RBM38 overexpression or silencing on cell cycle distribution were determined using flow cytometry. As shown in Fig. 2E, the overexpression of RBM38 decreased the percentage of cells in the $G_{0} / G_{1}$ phase compared with the pcDNA3.1 group, while the knockdown of RBM38 increased the $G_{0} / G_{1}$ phase ratio compared with the siR-NC group $(\mathrm{P}<0.01)$. Similarly, flow cytometric detection of apoptosis demonstrated that the overexpression of RBM38 significantly reduced apoptosis levels compared with the pcDNA3.1 group, while RBM38 silencing exerted the opposite effect (Fig. 2F). These findings suggested that RBM38 may promote $\mathrm{BC}$ cell proliferation by affecting apoptosis and the cell cycle.

miR-320b negatively regulates $R B M 38$. The miRanda algorithm (http://www.microrna.org/microrna/home.do) was used to predict the presence of a WT RBM38 binding site in the miR-320b sequence (Fig. 3A), which suggested the existence of an interaction between RBM38 and miR-320b during the progression of ADM-resistant $\mathrm{BC}$. To verify this prediction, a dual luciferase reporter assay was used to confirm the binding relationship between miR-320b and RBM38. The results indicated that WT RBM38 was able to directly bind to miR-320b to significantly reduce relative luciferase activity (Fig. 3B).

Transfection efficiencies of the miR-320b mimics and inhibitor in BC cells were determined using RT-qPCR; the results revealed that compared with the inhibitor NC group, the expression levels of miR-320b were downregulated in the miR-320b inhibitor group; conversely, compared with the mimics NC group, the expression levels of miR-320b were upregulated in the miR-320b mimics group (Fig. 3C). The association between RBM38 and miR-320b was determined using RT-qPCR with MCF-7/A cells transfected with the miR-320b inhibitor or miR-320b mimics. Following the transfection of cells with the miR-320b inhibitor, the expression levels of RBM38 were upregulated compared with the inhibitor NC group (Fig. 3D), while the expression levels of RBM38 were downregulated following transfection with the miR-320b mimics compared with the mimics NC group $(\mathrm{P}<0.001)$, suggesting that RBM38 may be negatively regulated by $\mathrm{miR}-320 \mathrm{~b}$.

miR-320b restores sensitivity to ADM and inhibits the resistance capacity of MCF-7/A cells. The expression levels of miR-320b in ADM-resistant BC tissues and cells (MCF-7/A) were also analyzed using RT-qPCR. The results demonstrated that miR-320b expression was downregulated in ADM-resistant $\mathrm{BC}$ tissues and cells compared with ADM-sensitive BC tissues and cells, respectively (Fig. 4A and B), which indicated that miR-320b may also affect drug resistance in BC. Subsequently, western blotting was performed to identify changes in RBM38 expression levels following transfection with either the miR-320b inhibitor or mimics. The results revealed that the miR-320b inhibitor upregulated the expression levels of RBM38 in MCF-7/A cells compared with the inhibitor NC group, while the overexpression of miR-320b downregulated RBM38 expression (Fig. 4C). To investigate whether miR-320b may be a favorable anti-resistance factor for ADM-resistant $\mathrm{BC}$, an MTT assay was conducted to determine changes in the cell inhibition rate of ADM in MCF-7/A cells. Notably, the silencing of miR-320b increased the $\mathrm{IC}_{50}$ value of $\mathrm{ADM}$ compared with the inhibitor NC group, while miR-320b mimics significantly decreased the $\mathrm{IC}_{50}$ value compared with the mimic NC group (Fig. 4D). These results indicated that the overexpression of miR-320b may effectively potentiate cell sensitivity towards ADM.

A Transwell assay was subsequently conducted to determine the effect of miR-320b on cellular invasion capacity. Compared with the respective NC groups, the number of invasive cells was increased in the miR-320b inhibitor group, but decreased in the miR-320b mimics group (Fig. 4E). These results suggested that miR-320b may be a favorable factor for inhibiting cellular invasiveness and restoring the sensitivity of resistant BC cells to ADM. Next, flow cytometry was used to investigate the cell cycle distribution and apoptosis levels. The results revealed that the ratio of cells in the $\mathrm{G}_{0} / \mathrm{G}_{1}$ phase was decreased (Fig. $4 \mathrm{~F}$ ) and apoptosis was reduced (Fig. 4G) following the inhibition of miR-320b compared with the inhibitor NC group. However, the overexpression of miR-320b significantly increased the number 

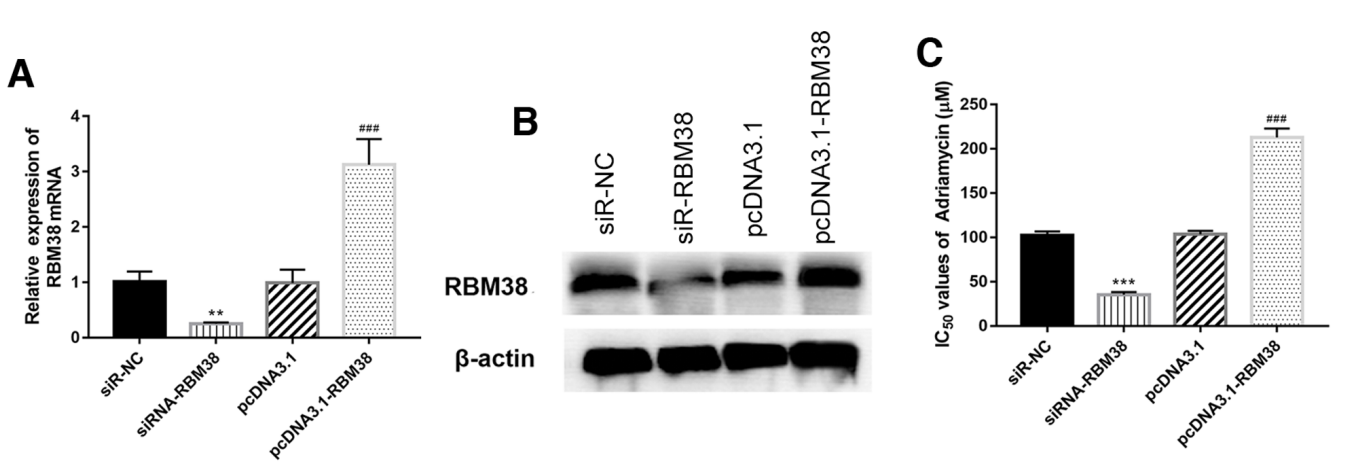

D
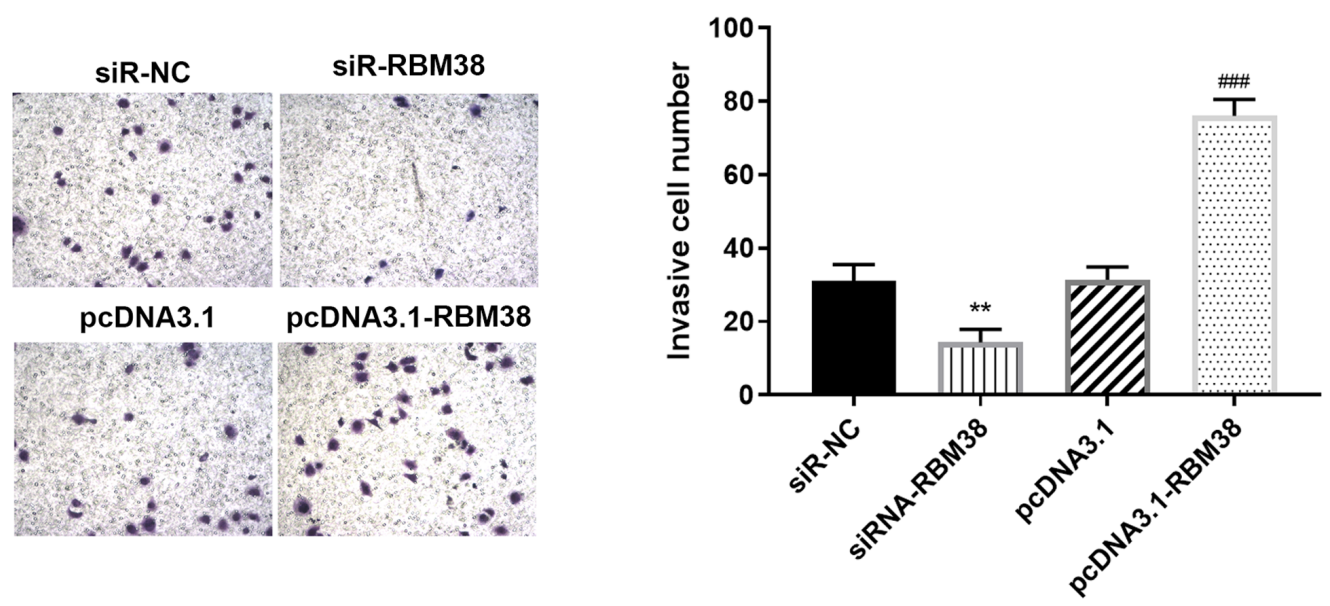

$\mathbf{E}$
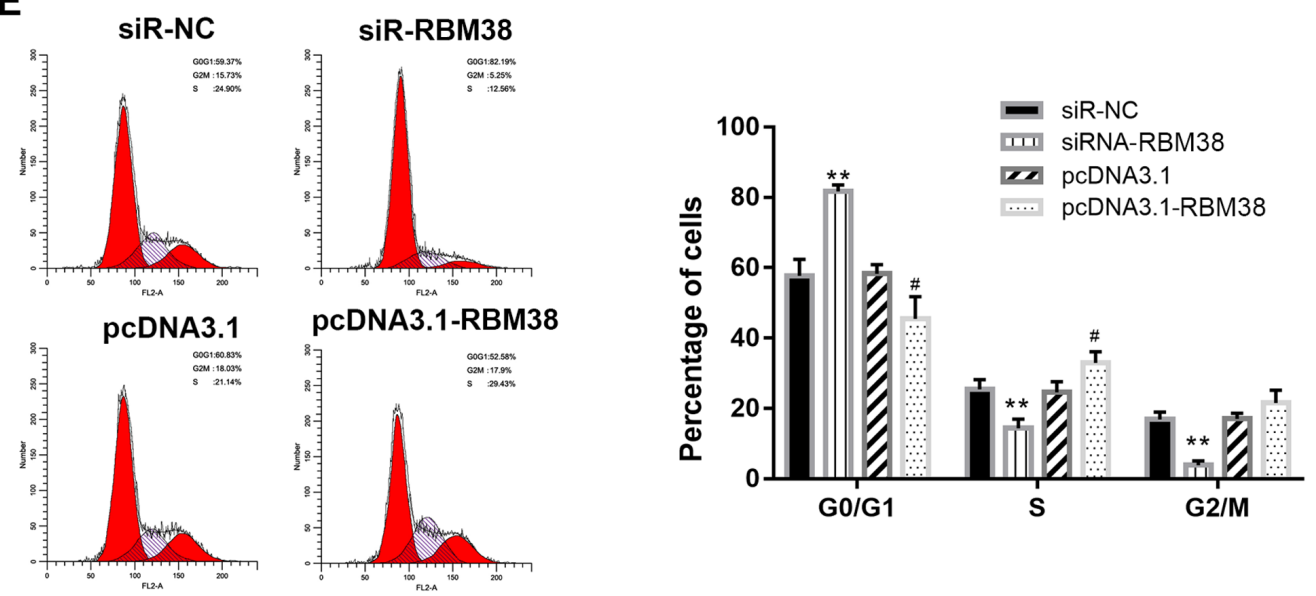

$\mathbf{F}$
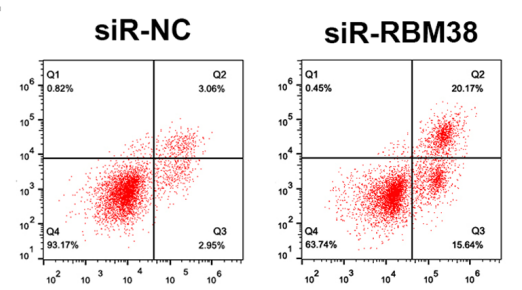

pcDNA3.1
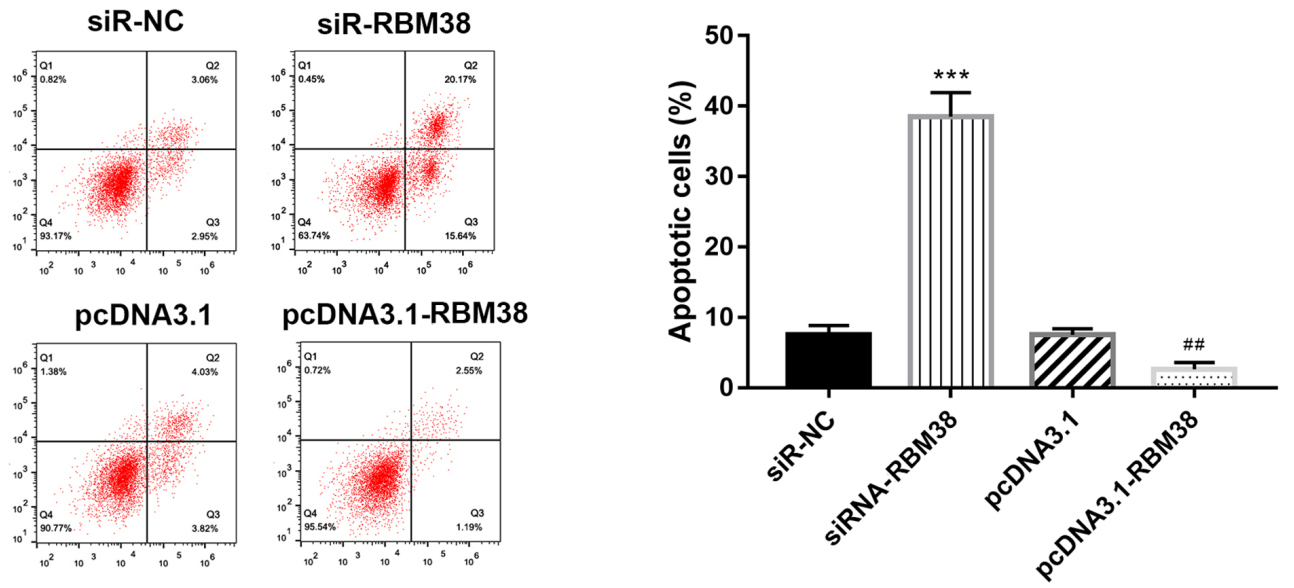

Figure 2. RBM38 impairs the sensitivity of BC cells to ADM, and inhibits the invasive ability of ADM-resistant BC cells. (A) mRNA and (B) protein expression levels of RBM38 in MCF-7/A cells. (C) MCF-7/A cells overexpressing RBM38 were less susceptible to ADM treatment. Furthermore, knockdown of RBM38 decreased the $\mathrm{IC}_{50}$ value of ADM. (D) Invasive ability of si-RBM38-transfected MCF-7/A cells, magnification, x100. (E) Cell cycle distribution and (F) apoptosis analyses were performed using flow cytometry. ${ }^{* *} \mathrm{P}<0.01$ and ${ }^{* * *} \mathrm{P}<0.001$ vs. si-NC; ${ }^{\#} \mathrm{P}<0.05,{ }^{\# \#} \mathrm{P}<0.01$ and ${ }^{\# \# \#} \mathrm{P}<0.001$ vs. pcDNA3.1. RBM38, RNA binding motif protein 38; BC, breast cancer; ADM, Adriamycin; A, ADM-resistant cells; si, small interfering RNA; NC, negative control. 
A

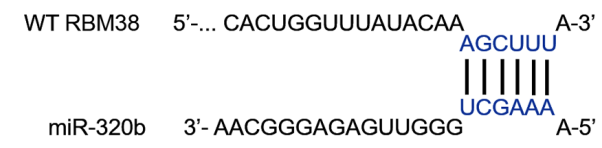

MUT RBM38 5'-... CACUGgUUUAUACAA UCGAAAA -3'

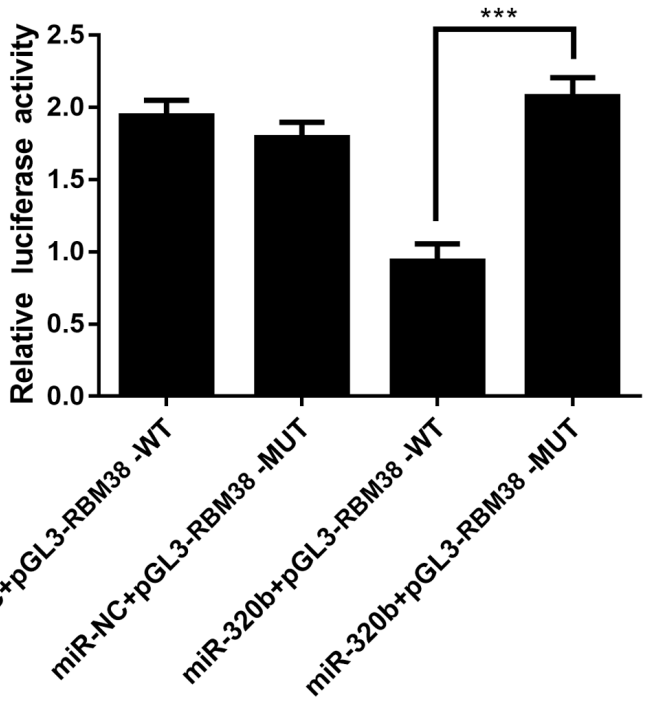

C

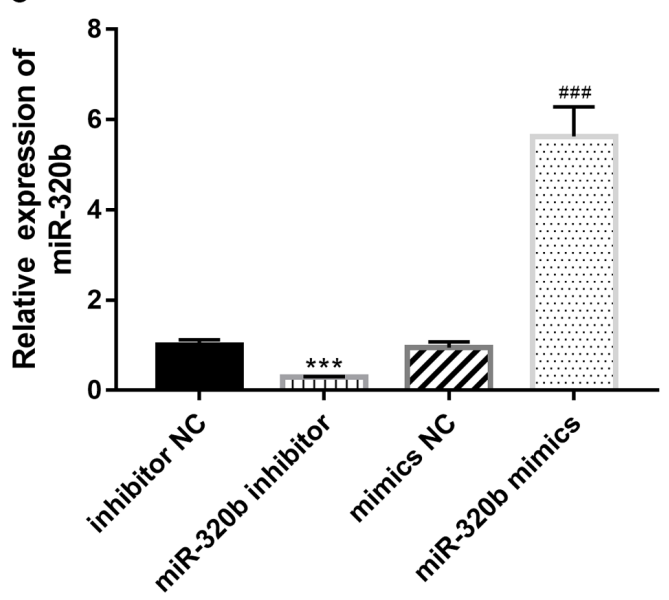

D

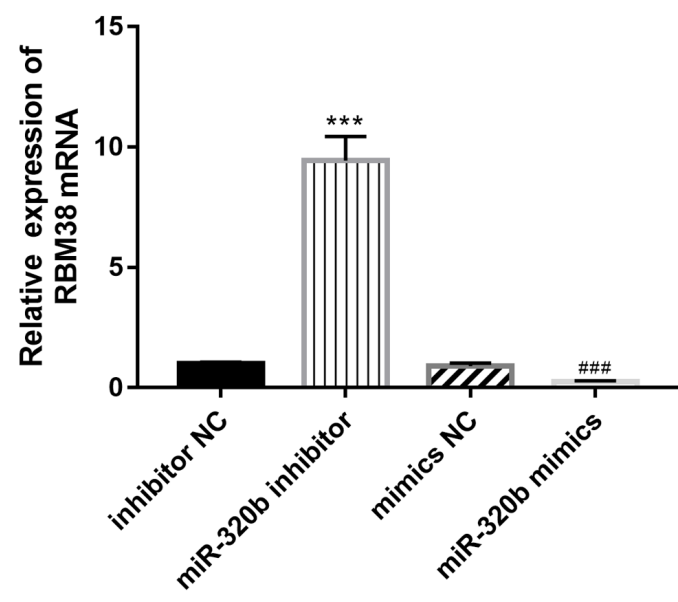

Figure 3. RBM38 interacts with miR-320b. (A) Bioinformatics prediction indicated the existence of a binding site between RBM38 and miR-320b. (B) Dual luciferase reporter assays further validated the association between miR-320b and RBM38. Expression levels of (C) miR-320b and (D) RBM38 mRNA in MCF-7/A cells following the overexpression or knockdown of miR-320b. ${ }^{* * *} \mathrm{P}<0.001$ vs. inhibitor NC; ${ }^{* \#} \mathrm{P}<0.001$ vs. mimics NC. RBM38, RNA binding motif protein 38; miR, microRNA; NC, negative control; ADM, Adriamycin; A, ADM-resistant cells; WT, wild-type; MUT, mutant.

of cells in the $\mathrm{G}_{0} / \mathrm{G}_{1}$ phase (Fig. $4 \mathrm{~F}$ ), as well as the apoptotic rate (Fig. 4G) compared with the mimic NC group. These findings suggested that miR-320b may be a crucial factor involved in promoting the apoptosis, and inhibiting the proliferation, of ADM-resistant BC cells.

RBM38 rescues miR-230b-induced resistance by mediating the expression levels of proteins associated with apoptosis, drug resistance and the cell cycle. The association between miR-320b and RBM38 was further investigated by transfecting MCF-7/A cells with an miR-320b inhibitor, or co-transfection with an miR-320b inhibitor and si-RBM38. The transfection efficiency was determined using RT-qPCR. miR-320b inhibition significantly upregulated the level of RBM38 mRNA compared with the inhibitor NC group (Fig. 5A), and siR-RBM38 markedly reduced this trend compared with the miR-320b inhibitor group (Fig. 5A); the resultant trend was also demonstrated by western blotting (Fig. 5B). Subsequently, Transwell assays were conducted to detect any alterations in the invasive capacity of the different groups. The results revealed that miR-320b inhibition significantly increased the invasive cell number compared with the inhibitor NC group (Fig. 5C). However, the combined knockdown of RBM38 reversed the effect of miR-320b silencing compared with the miR-320b inhibitor alone group (Fig. 5C). Furthermore, flow cytometric analysis demonstrated that apoptotic rate was notably increased in the miR-320b inhibitor and si-RBM38 co-transfection group compared with the miR-320b inhibitor alone group (Fig. 5D). Cell cycle analysis also demonstrated that the inhibition of miR-320b inhibited $\mathrm{G}_{0} / \mathrm{G}_{1}$ phase arrest, while the silencing of RBM38 further rescued the effect induced by miR-320b inhibition Fig. 5E).

The exact underlying mechanism of action of the RBM38/miR-320b axis in ADM resistance remains to be determined. Hence, the present study further investigated various common tumor modulatory signaling pathways and the expression levels of proteins related to the cell cycle, apoptosis and drug resistance, to determine their degree of contribution to the regulatory effects of the miR-320b/RBM38 signaling axis. The protein expression levels of the selected factors were indicated in Fig. 6A, and the quantification results revealed that the expression levels of MDR1 (Fig. 6B) and BCRP (Fig. 6C) were upregulated in miR-320b inhibitor-transfected cells compared with the inhibitor NC group, and downregulated in RBM38-silenced cells compared with the miR-320b inhibitor group. The levels of Bax were 

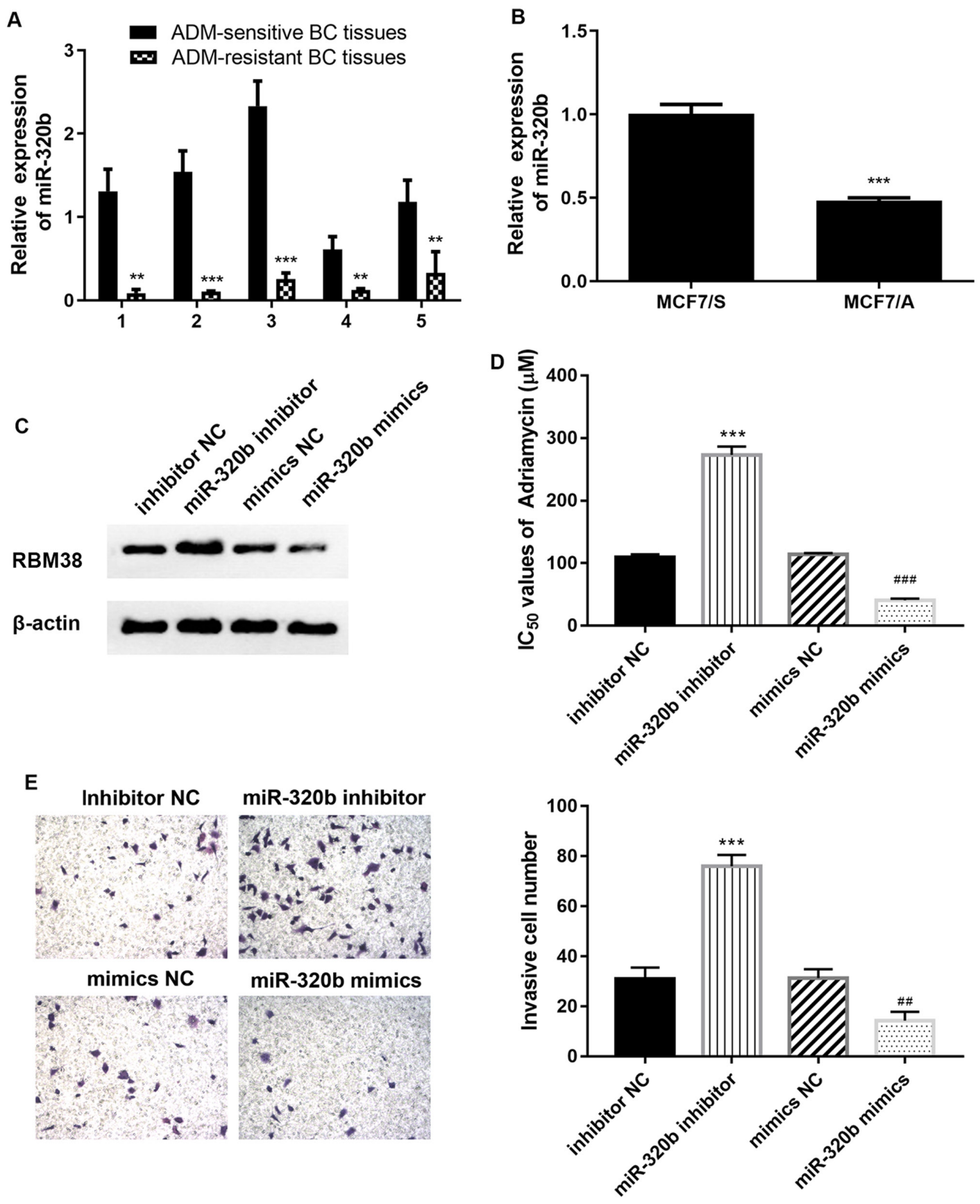

Figure 4. Continued.

downregulated (Fig. 6D), while those of Bcl-2 were upregulated (Fig. 6E), following miR-320b inhibition. . In addition, western blot analysis demonstrated that transfection with the miR-320b inhibitor upregulated the p-PI3K/PI3K (Fig. 6F) and p-AKT/AKT (Fig. 6G) ratios compared with the inhibitor NC group. Conversely, co-transfection with si-RBM38 and the miR-320b inhibitor significantly downregulated the $\mathrm{p}-\mathrm{PI} 3 \mathrm{~K} / \mathrm{PI} 3 \mathrm{~K}$ and $\mathrm{p}-\mathrm{AK} \mathrm{T} / \mathrm{AK} \mathrm{T}$ ratios compared with the miR-320b inhibitor alone group. These findings indicated that the miR-320b/RBM38 signaling axis may regulate the activation of the PI3K/AKT signaling pathway in ADM-resistant BC cells. Collectively, the knockdown of miR-320b was found to promote $\mathrm{BC}$ cell resistance to ADM by influencing the PI3K/AKT signaling pathway and apoptosis, as well as the expression levels of drug resistance-related proteins, while silencing RBM38 reversed the effects induced by the miR-320b inhibitor.

\section{Discussion}

There are currently a number of effective chemotherapeutic drugs on the market, including ADM, tamoxifen and paclitaxel (30-32). However, the clinical therapeutic outcome is far from satisfactory. Due to the gradual development of drug resistance, patients with $\mathrm{BC}$ are only able to benefit from these treatment options at the early stages of disease (24). The development of therapeutic tolerance is the primary barrier to a complete cure for BC. Hence, there is an urgent requirement for further studies to overcome the challenge associated with drug resistance in BC treatment. 

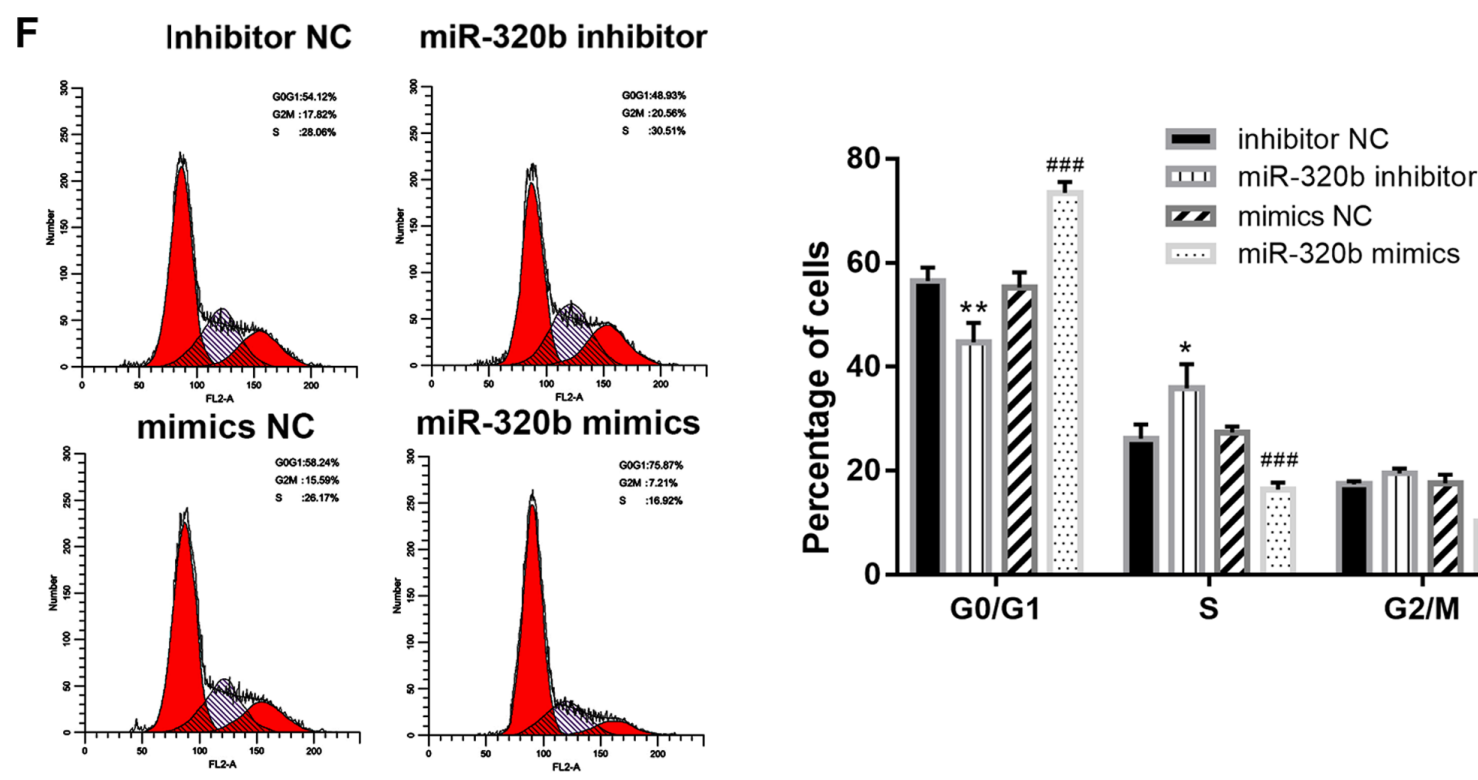

G
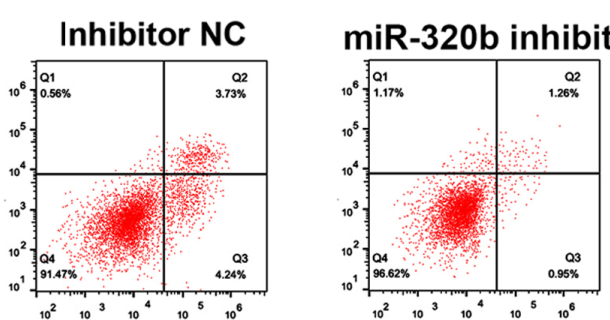

mimics NC
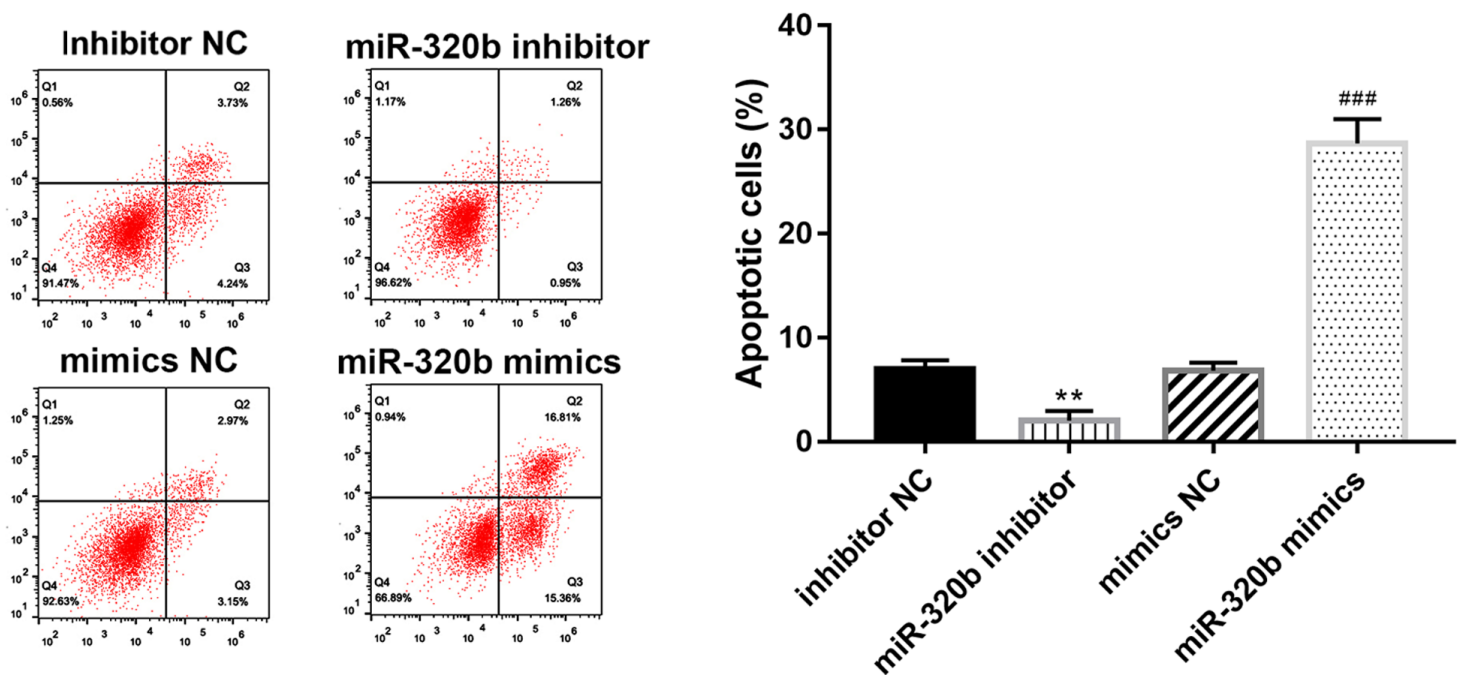

Figure 4. miR-320b promotes the resistance of BC cells to ADM. miR-320b expression levels were downregulated in (A) ADM-resistant BC tissues and (B) MCF-7/A cells compared with ADM-sensitive BC tissues and MCF-7/S cells, respectively. (C) Western blotting demonstrated that RBM38 expression was downregulated in the miR-320b mimics group. (D) miR-320b-inhibited MCF-7/A cells were less susceptible to ADM, and overexpression of miR-320b decreased the $\mathrm{IC}_{50}$ value of ADM. (E) Transwell assays indicated that miR-320b inhibited the invasive ability of ADM-resistant BC cells, magnification, $\mathrm{x} 100$. (F) Cell cycle distribution and $(\mathrm{G})$ apoptosis were analyzed via flow cytometry. ${ }^{*} \mathrm{P}<0.05,{ }^{* *} \mathrm{P}<0.01$ and ${ }^{* * *} \mathrm{P}<0.001$ vs. inhibitor $\mathrm{NC}$, or as indicated; ${ }^{\# \#} \mathrm{P}<0.01$ and

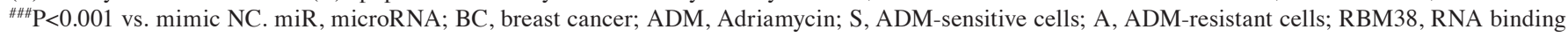
motif protein 38 ; $\mathrm{NC}$, negative control.

Previous studies have reported that the expression levels of specific miRNAs, including miRNA-449, miR-140 and miR-200a, are dysregulated in BC (11-13), and that miRNAs may participate in the chemoresistance of $\mathrm{BC}(33,34)$. miRNAs are known to inhibit gene expression by either inhibiting transcription or inducing degradation of their target mRNAs (35). Du et al (36) demonstrated that the overexpression of miR-137 increased the sensitivity of BC cell-derived tumors to ADM by targeting dual specificity phosphatase 4 , both in vitro and in vivo. The miR-202-5p/PTEN signaling axis was also reported to mediate ADM resistance in $\mathrm{BC}$ cells by regulating the PI3K/AKT signaling pathway (37). In addition, ATP binding cassette subfamily B member 4 was found to contribute to acquired ADM resistance in BC cells in vitro (38). However, to the best of our knowledge, the effect of the RBM38/miR-320b signaling axis in ADM-resistant $\mathrm{BC}$ remains unclear.
Although current studies have indicated that RBM38 may be a favorable factor in preventing the development of $\mathrm{BC}$, the present study revealed that this may not be the case in drug-resistant BC. First, the results revealed that RBM38 expression was upregulated in ADM-resistant BC tissues and cells (MCF-7/A), which indicated that RBM38 may be a key factor in the development of ADM resistance in BC. Further investigations demonstrated that the overexpression of RBM38 increased the $\mathrm{IC}_{50}$ value of ADM in MCF-7/A cells, which supported that RBM38 may decrease the sensitivity of $\mathrm{BC}$ cells to ADM. In addition, the overexpression of RBM38 intensified the drug resistance of MCF-7/A cells, by increasing the invasiveness and inhibiting the apoptosis of cells, as well as accelerating cell cycle progression. These findings indicated that RBM38 may play a significant role in the drug resistance of MCF-7/A cells to ADM. 
A

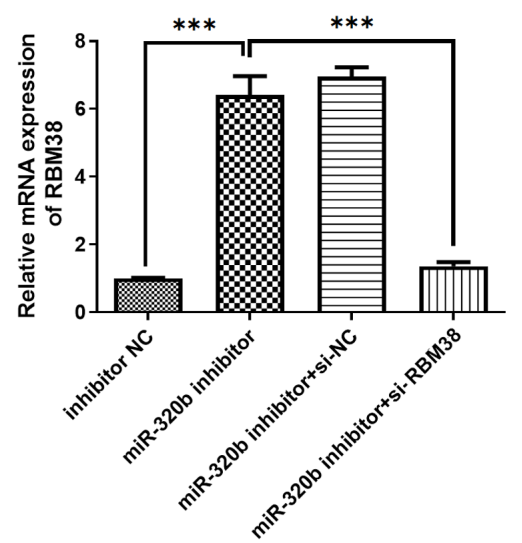

C Inhibitor NC

miR-320b inhibitor

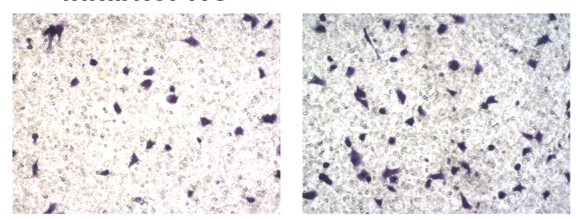

miR-320b inhibitor+si-NC miR-320binhibitor+si-RBM38

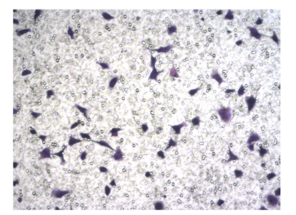

D Inhibitor NC
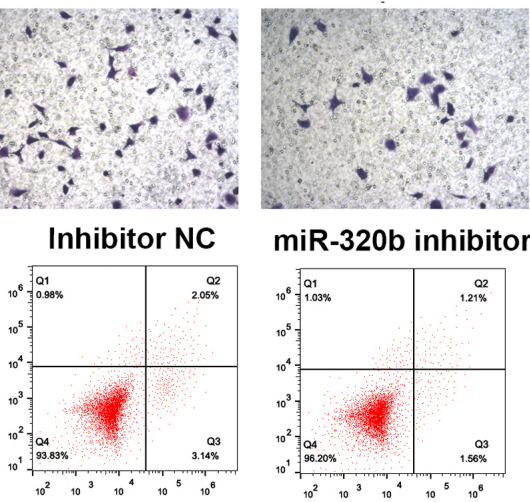

miR-320b inhibitor

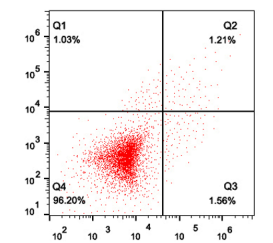

miR-320b inhibitor+si-NC miR-320binhibitor+si-RBM38
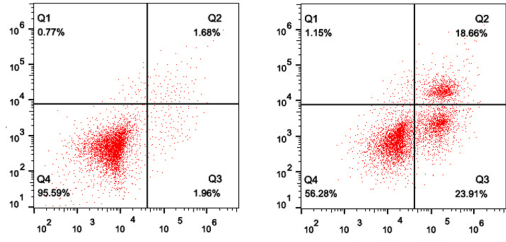

E
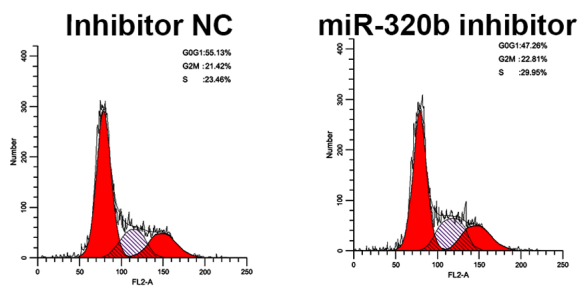

miR-320b inhibitor+si-NC miR-320binhibitor +si-RBM38
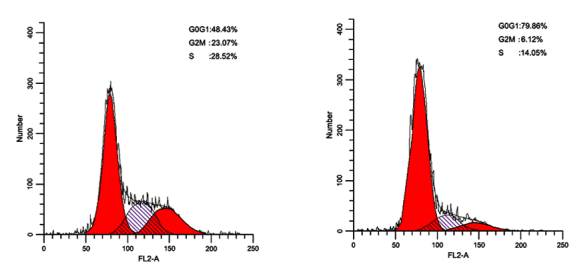

B

RBM38

\section{$\beta$-actin}
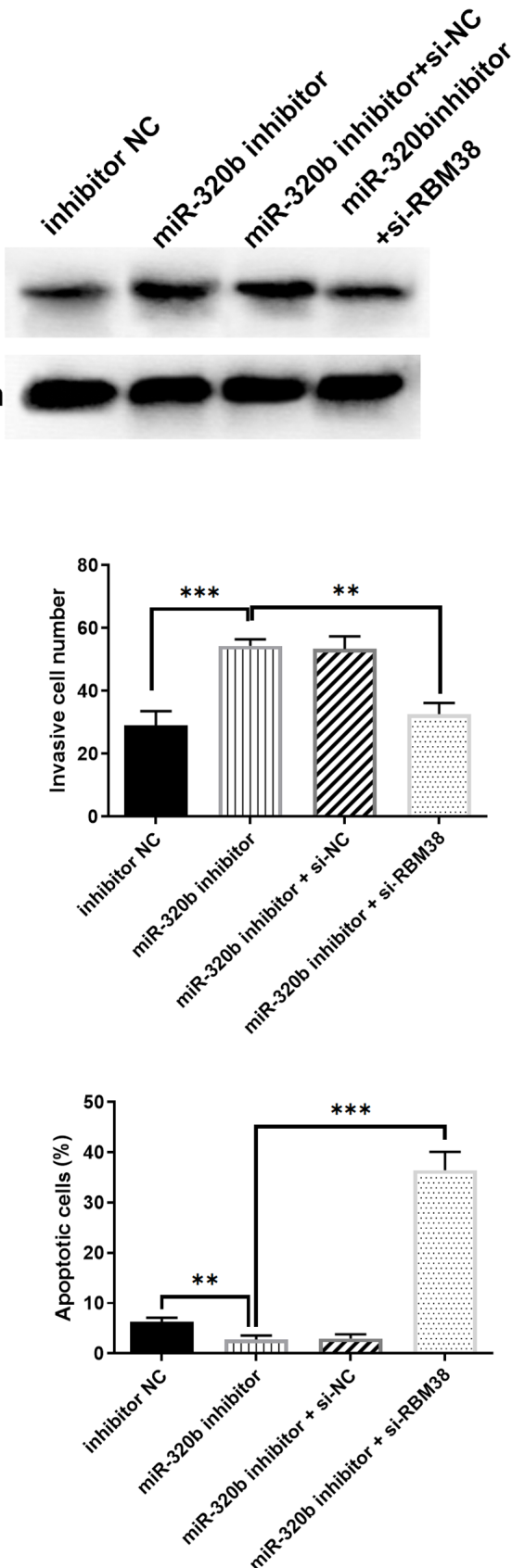

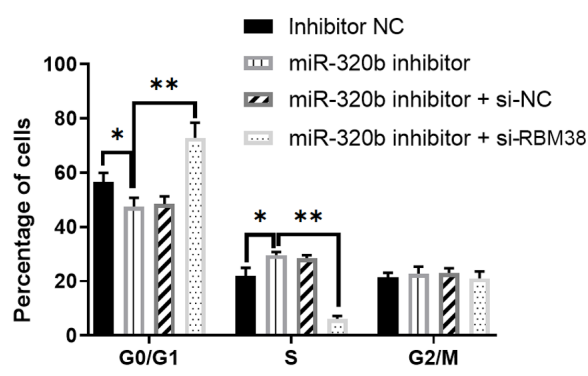

Figure 5. RBM38 reverses the effects of miR-320b. (A) mRNA and (B) protein expression levels of RBM38 in MCF-7/A cells were determined using reverse transcription-quantitative PCR and western blotting, respectively. (C) Transwell assays were used to determine invasive ability across different groups, magnification, $x 100$. (D) Apoptosis and (E) cell cycle distribution were analyzed using flow cytometry. ${ }^{*} \mathrm{P}<0.05,{ }^{* *} \mathrm{P}<0.01$ and ${ }^{* * *} \mathrm{P}<0.001$ as indicated. RBM38, RNA binding motif protein 38; miR, microRNA; ADM, Adriamycin; A, ADM-resistant cells; si, small interfering RNA. 
A

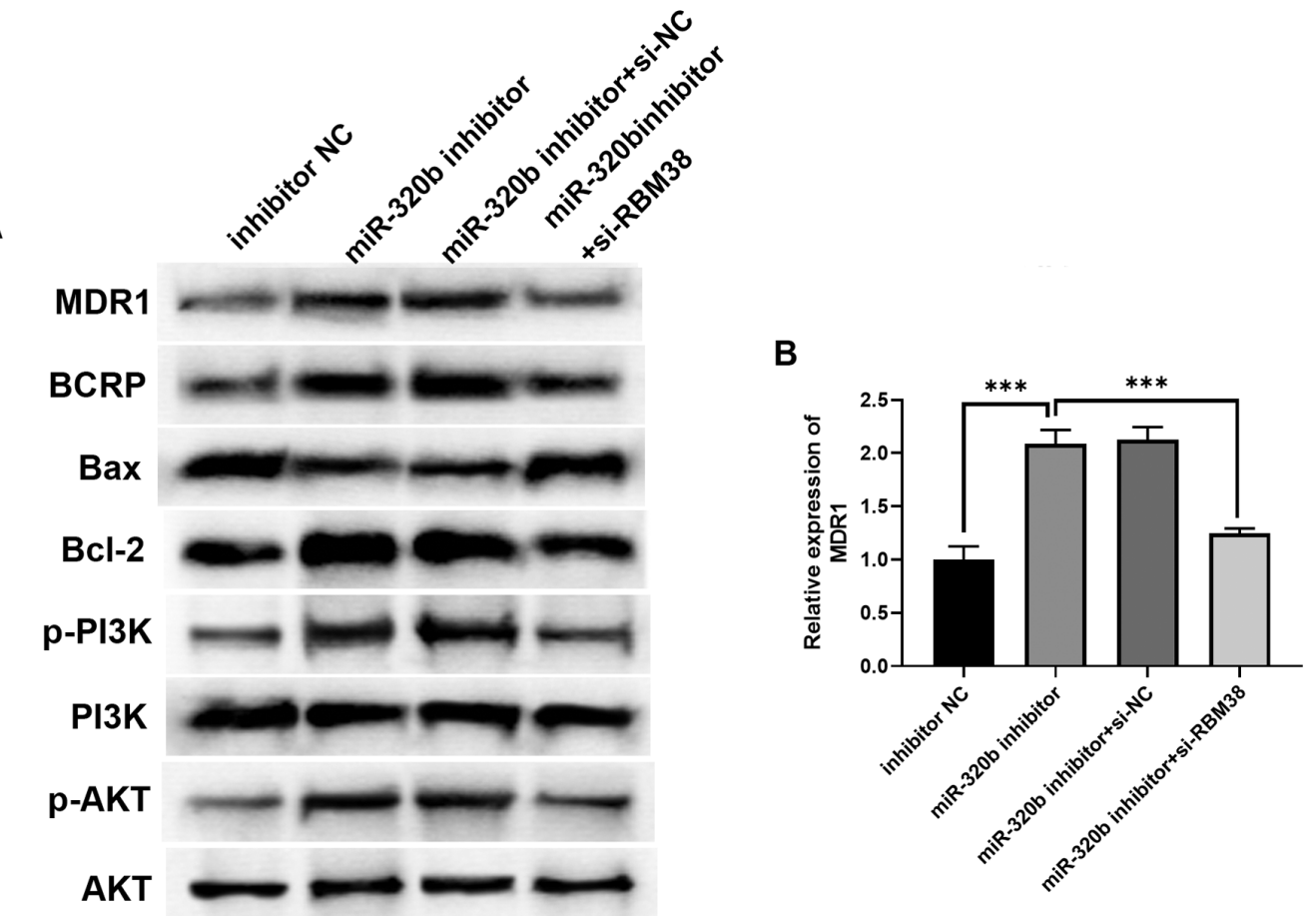

$\beta$-actin

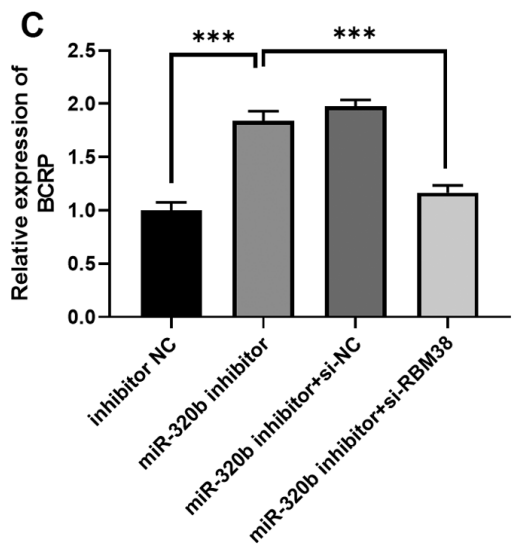

D

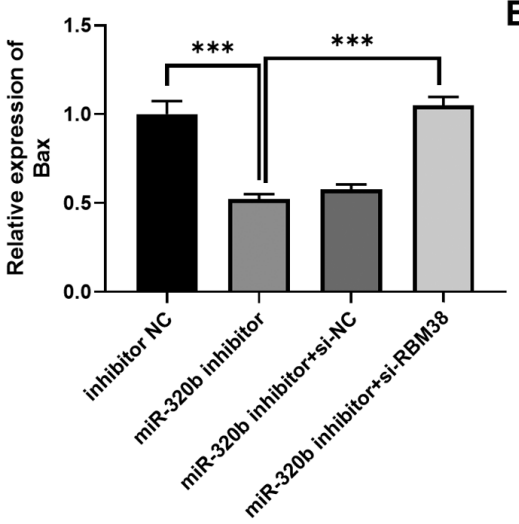

E

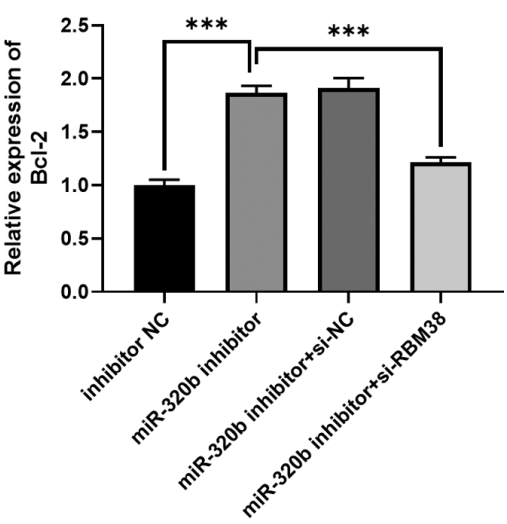

$\mathbf{F}$

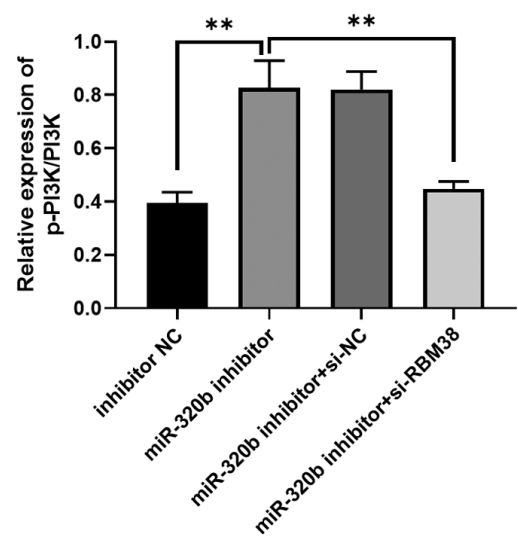

G

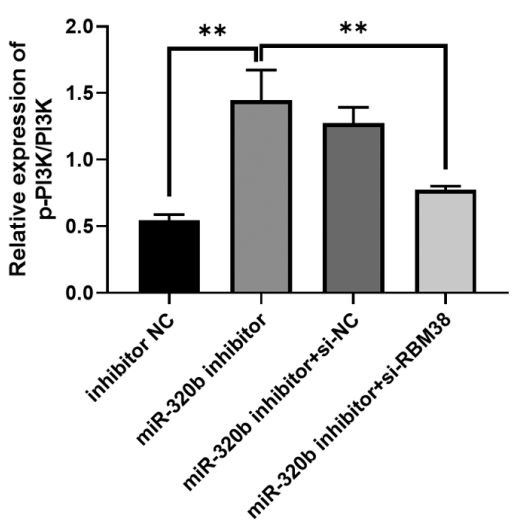

Figure 6. RBM38 affects ADM resistance in BC by moderating the expression levels of proteins related to apoptosis, drug resistance and the cell cycle. (A) Western blotting demonstrated that the RBM38/miR-320b signaling axis regulated BC cell biological processes by altering the expression levels of PI3K/AKT signaling pathway-, cell cycle- and drug resistance-related proteins. The quantification of (B) MDR1, (C) BCRP,(D) Bax, (E) Bcl-2, (F) p-PI3K/PI3K and (G) p-AKT/AKT. ${ }^{* *} \mathrm{P}<0.01$ and ${ }^{* * *} \mathrm{P}<0.001$ as indicated. BM38, RNA binding motif protein 38; miR, microRNA; si, small interfering RNA; MDR1, multiple drug resistant protein 1; BCRP, breast cancer resistance protein; $\mathrm{p}-$, phosphorylated.

miR-320b has been reported to play an important role in numerous types of disease, including glioma, carotid atheroscle- rosis, colorectal cancer and coronary heart disease $(18,39,40)$. In the present study, the results of the dual luciferase reporter 
assay identified a binding site between RBM38 and miR-320b. Thus, the association between miR-320b and RBM38 was further investigated. The expression levels of RBM38 were found to be negatively regulated by miR-320b. In addition, miR-320b expression was discovered to be downregulated in ADM-resistant BC tissues and cells. Furthermore, the overexpression of miR-320b reversed ADM resistance, inhibited invasiveness, promoted apoptosis and arrested the MCF-7/A cell cycle at the $G_{0} / G_{1}$ phase; the knockdown of miR-320b exerted the opposite effect. Notably, RBM38-knockdown rescued the effects of the miR-320b inhibitor, indicating the presence of a negative regulatory relationship between RBM38 and miR-320b. Investigations aiming to determine the underlying mechanism of the miR-320b/RBM38 signaling pathway revealed that the inhibition of $\mathrm{miR}-320 \mathrm{~b}$ in MCF-7/A cells led to the activation of the PI3K/AKT signaling pathway, as well as the regulation of apoptosis-related (Bax and $\mathrm{Bcl}-2$ ) and drug resistance-related (MDR1 and BCRP) proteins, which was found to contribute to ADM resistance. These results suggested that the miR-320b/RBM38 signaling axis may play a key role in ADM resistance in BC by regulating cellular proliferation, invasiveness, apoptosis and the cell cycle, which provides potential novel markers for diagnosing and overcoming drug resistance in BC. However, there are some limitations to the current study. For example, the tissue sample size was small. Furthermore, whether miR-320b and RBM38 can be used to predict the disease-free survival rate of patients with BC, and the prognostic abilities of miR-320b and RBM38 in $\mathrm{BC}$, were not investigated. These points will be addressed in future studies. Finally, additional BC cell lines should be used to further investigate the functions of the miR-320b/RBM38 signaling axis in the drug resistance of BC cells to ADM.

In conclusion, the findings of the present study indicated that RBM38, which is negatively regulated by $\mathrm{miR}-320 \mathrm{~b}$, accelerated the development of ADM resistance in BC cells by activating the PI3K/AKT signaling pathway. Thus, the RBM38/miR-320b signaling axis may represent a novel target for alleviating drug resistance in $\mathrm{BC}$.

\section{Acknowledgements}

Not applicable.

\section{Funding}

No funding was received.

\section{Availability of data and materials}

The datasets used and/or analyzed during the current study are available from the corresponding author on reasonable request.

\section{Authors' contributions}

JK and KN designed the study; HX and JL performed the experiments; JK, KN and HX conducted the statistical analysis; JK and KN drafted the manuscript; and JL revised and proofread the manuscript. JK and JL confirm the authenticity of all the raw data. All authors have read and approved the final manuscript.

\section{Ethics approval and consent to participate}

The experimental protocol was approved by the Ethics Committee of The Affiliated Hospital of Nantong University (Nantong, China; approval no. 2019032174) and was performed in accordance with the principles of the 1964 Declaration of Helsinki. All patients provided written informed consent prior to study commencement.

\section{Patient consent for publication}

Not applicable.

\section{Competing interests}

The authors declare that they have no competing interests.

\section{References}

1. Akram M, Iqbal M, Daniyal M and Khan AU: Awareness and current knowledge of breast cancer. Biol Res 50: 33, 2017.

2. Zaidi Z and Dib HA: The worldwide female breast cancer incidence and survival, 2018. Cancer Res: Jul 1, 2019 (Epub ahead of print). doi: 10.1158/1538-7445.AM2019-4191.

3. Ellis LM and Hicklin DJ: Resistance to targeted therapies: Refining anticancer therapy in the era of molecular oncology. Clin Cancer Res 15: 7471-7478, 2009.

4. Network CGA; Cancer Genome Atlas Network: Comprehensive molecular portraits of human breast tumours. Nature 490: 61-70, 2012.

5. Daniyal A, Santoso I, Gunawan NHP, Barliana MI and Abdulah R: Genetic Influences in Breast Cancer Drug Resistance. Breast Cancer (Dove Med Press) 13: 59-85, 2021.

6. Ji X, Lu Y, Tian H, Meng X, Wei M and Cho WC: Chemoresistance mechanisms of breast cancer and their countermeasures. Biomed Pharmacother 114: 108800, 2019.

7. Hu W, Tan C, He Y, Zhang G, Xu Y and Tang J: Functional miRNAs in breast cancer drug resistance. OncoTargets Ther 11: 1529-1541, 2018

8. Khordadmehr M, Shahbazi R, Ezzati H, Jigari-Asl F, Sadreddini S and Baradaran B: Key microRNAs in the biology of breast cancer; emerging evidence in the last decade. J Cell Physiol 234: 8316-8326, 2019.

9. Hanna J, Hossain GS and Kocerha J: The potential for microRNA therapeutics and clinical research. Front Genet 10: 478, 2019.

10. Si W, Shen J, Zheng H and Fan W: The role and mechanisms of action of microRNAs in cancer drug resistance. Clin Epigenetics 11: $25,2019$.

11. Tormo E, Ballester S, Adam-Artigues A, Burgués O, Alonso E, Bermejo B, Menéndez S, Zazo S, Madoz-Gúrpide J, Rovira A, et al: The miRNA-449 family mediates doxorubicin resistance in triple-negative breast cancer by regulating cell cycle factors. Sci Rep 9: 5316, 2019.

12. Lu X, Liu R, Wang M, Kumar AK, Pan F, He L, Hu Z and Guo Z: MicroRNA-140 impedes DNA repair by targeting FEN1 and enhances chemotherapeutic response in breast cancer. Oncogene 39: 234-247, 2020

13. Yu SJ, Yang L, Hong Q, Kuang XY, Di GH and Shao ZM: MicroRNA-200a confers chemoresistance by antagonizing TP53INP1 and YAP1 in human breast cancer. BMC Cancer 18: 74, 2018.

14. Mulrane L, McGee SF, Gallagher WM and O'Connor DP: miRNA dysregulation in breast cancer. Cancer Res 73: 6554-6562, 2013.

15. Rupaimoole R and Slack FJ: MicroRNA therapeutics: Towards a new era for the management of cancer and other diseases. Nat Rev Drug Discov 16: 203-222, 2017.

16. Wang H, Cao F, Li X, Miao H, e J, Xing J and Fu CG: miR-320b suppresses cell proliferation by targeting c-Myc in human colorectal cancer cells. BMC Cancer 15: 748, 2015.

17. Li Y, Tang X, He Q, Yang X, Ren X, Wen X, Zhang J, Wang Y, Liu $\mathrm{N}$ and Ma J: Overexpression of mitochondria mediator gene TRIAP1 by miR-320b loss is associated with progression in nasopharyngeal carcinoma. PLoS Genet 12: e1006183, 2016. 
18. Lv GY, Miao J and Zhang XL: Long noncoding RNA XIST promotes osteosarcoma progression by targeting Ras-related protein RAP2B via miR-320b. Oncol Res 26: 837-846, 2018

19. Wu X, Wang Y, Zhong W, Cheng $\mathrm{H}$ and Tian Z: RNA binding protein RNPC1 suppresses the stemness of human endometria cancer cells via stabilizing MST1/2 mRNA. Med Sci Monit 26: e921389, 2020

20. Cho SJ, Jung YS, Zhang J and Chen X: The RNA-binding protein RNPC1 stabilizes the mRNA encoding the RNA-binding protein $\mathrm{HuR}$ and cooperates with HuR to suppress cell proliferation. J Biol Chem 287: 14535-14544, 2012.

21. Shi L, Xia T-S, Wei X-L, Zhou W, Xue J, Cheng L, Lou P, Li C, Wang Y, Wei JF, et al: Estrogen receptor (ER) was regulated by RNPC1 stabilizing mRNA in ER positive breast cancer. Oncotarget 6: 12264-12278, 2015.

22. Zheng L, Zhang Z, Zhang S, Guo Q, Zhang F, Gao L, Ni H, Guo X, Xiang C and Xi T: RNA binding protein RNPC1 inhibits breast cancer cell metastasis via activating STARD13-correlated ceRNA network. Mol Pharm 15: 2123-2132, 2018.

23. Hernandez-Aya LF and Gonzalez-Angulo AM: Adjuvant systemic therapies in breast cancer. Surg Clin North Am 93 473-491, 2013.

24. Ponnusamy L, Mahalingaiah PKS and Singh KP: Treatment schedule and estrogen receptor-status influence acquisition of doxorubicin resistance in breast cancer cells. Eur J Pharm Sci 104: 424-433, 2017.

25. Xue J-Q, Xia T-S, Liang X-Q, Zhou W, Cheng L, Shi L, Wang Y and Ding Q: RNA-binding protein RNPC1: Acting as a tumor suppressor in breast cancer. BMC Cancer 14: 322, 2014.

26. Livak KJ and Schmittgen TD: Analysis of relative gene expression data using real-time quantitative PCR and the 2(- $\Delta \Delta \mathrm{C}(\mathrm{T}))$ method. Methods 25: 402-408, 2001.

27. Zhong ZF, Yu HB, Wang CM, Qiang WA, Wang SP, Zhang JM, $\mathrm{Yu}$ H, Cui L, Wu T, Li DQ, et al: Furanodiene induces extrinsic and intrinsic apoptosis in doxorubicin-resistant MCF-7 breast cancer cells via NF- $\mathrm{BB}$-independent mechanism. Front Pharmacol 8: 648, 2017.

28. Gao HL, Xia YZ, Zhang YL, Yang L and Kong LY: Vielanin P enhances the cytotoxicity of doxorubicin via the inhibition of PI3K/Nrf2-stimulated MRP1 expression in MCF-7 and K562 DOX-resistant cell lines. Phytomedicine 58: 152885, 2019.

29. Li YS, Zhao DS, Liu XY, Liao YX, Jin HW, Song GP and Cui ZN: Synthesis and biological evaluation of 2,5-disubstituted furan derivatives as P-glycoprotein inhibitors for Doxorubicin resistance in MCF-7/ADR cell. Eur J Med Chem 151: 546-556, 2018.
30. Muss HB, White DR, Richards F II, Cooper MR, Stuart JJ, Jackson DV, Rhyne L and Spurr CL: Adriamycin versus methotrexate in five-drug combination chemotherapy for advanced breast cancer: A randomized trial. Cancer 42: 2141-2148, 1978.

31. Valero V,Jones SE, Von Hoff DD, BooserDJ,Mennel RG, Ravdin PM, Holmes FA, Rahman Z, Schottstaedt MW, Erban JK, et al: A phase II study of docetaxel in patients with paclitaxel-resistant metastatic breast cancer. J Clin Oncol 16: 3362-3368, 1998.

32. Riggins RB, Schrecengost RS, Guerrero MS and Bouton AH: Pathways to tamoxifen resistance. Cancer Lett 256: 1-24, 2007.

33. Chen X, Lu P, Wang DD, Yang SJ, Wu Y, Shen H-Y, Zhong SL, Zhao JH and Tang JH: The role of miRNAs in drug resistance and prognosis of breast cancer formalin-fixed paraffin-embedded tissues. Gene 595: 221-226, 2016.

34. Majumder S and Jacob ST: Emerging role of microRNAs in drug-resistant breast cancer. Gene Expr 15: 141-151, 2011.

35. Lu TX and Rothenberg ME: MicroRNA.J Allergy Clin Immunol 141: 1202-1207, 2018.

36. Du F, Yu L, Wu Y, Wang S, Yao J, Zheng X, Xie S, Zhang S, Lu X, Liu Y, et al: miR-137 alleviates doxorubicin resistance in breast cancer through inhibition of epithelial-mesenchymal transition by targeting DUSP4. Cell Death Dis 10: 922, 2019.

37. Liu T, Guo J and Zhang X: MiR-202-5p/PTEN mediates doxorubicin-resistance of breast cancer cells via PI3K/Akt signaling pathway. Cancer Biol Ther 20: 989-998, 2019.

38. Huang JF, Wen CJ, Zhao GZ, Dai Y, Li Y, Wu LX and Zhou HH: Overexpression of ABCB4 contributes to acquired doxorubicin resistance in breast cancer cells in vitro. Cancer Chemother Pharmacol 82: 199-210, 2018.

39. Zhang R, Qin Y, Zhu G, Li Y and Xue J: Low serum miR-320b expression as a novel indicator of carotid atherosclerosis. J Clin Neurosci 33: 252-258, 2016,

40. Lv QL, Du H, Liu YL, Huang YT, Wang GH, Zhang X, Chen SH and Zhou HH: Low expression of microRNA-320b correlates with tumorigenesis and unfavorable prognosis in glioma. Oncol Rep 38: 959-966, 2017.

This work is licensed under a Creative Commons Attribution-NonCommercial-NoDerivatives 4.0 International (CC BY-NC-ND 4.0) License. 